\title{
Influence of Sustain Pulse-width on Electrical Characteristics and Luminous Efficiency in Surface Discharge of AC-PDP
}

\author{
Yong-Whan Jeong ${ }^{\text {a }}$, Jin-Man Jeoung, and Eun-Ha Choi \\ Charged Particle Beam and Plasma Laboratory, Department of. Electrophysics, PDP Research \\ Center, Kwangwoon University, 447-1 Wolgye-dong, Nowon-gu, Seoul 139-701, Korea \\ ${ }^{a}$ E-mail : yjeong@paran.com
}

(Received November 21 2005, Accepted December 12 2005)

\begin{abstract}
Influences of sustain pulse-width on electrical characteristics and luminous efficiency are experimentally investigated for surface discharge of AC-PDP. A square pulse with variable duty ratio and fixed rising time of $300 \mathrm{~ns}$ has been used in the experiment. It is found that the memory coefficient is significantly increased at the critical pulse-width. And the wall charges and wall voltages as well as capacitances are experimentally measured by $\mathrm{Q}-\mathrm{V}$ analysis method along with the voltage margin relation, in terms of the sustain pulse-width in the range of $1 \mu \mathrm{s}$ to $5 \mu \mathrm{s}$ under driving frequency of $10 \mathrm{kHz}$ to $180 \mathrm{kHz}$. And the luminous efficiency is also experi-mentally investigated in above range of sustain pulse-width with driving frequency of 10 $\mathrm{kHz}$ to $180 \mathrm{kHz}$. It is noted that the luminous efficiency for $10 \mathrm{kHz}$ and $180 \mathrm{kHz}$ are $1.29 \mathrm{~lm} / \mathrm{W}$ and $0.68 \mathrm{~lm} / \mathrm{W}$ respectively, since the power consumption for $10 \mathrm{kHz}$ is much less than that for $180 \mathrm{kHz}$. It has been concluded that the optimal sustain pulse-width is in the range of $2.5 \sim 4.5$ $\mu \mathrm{s}$ under driving frequency range of $10 \mathrm{kHz}$ and $60 \mathrm{kHz}$, and in the range of $1.5 \sim 2.5 \mu \mathrm{s}$ under driving frequency range of $120 \mathrm{kHz}$ and $180 \mathrm{kHz}$ based on observation of memory coefficient, and wall voltage as well as luminous efficiency.
\end{abstract}

Keywords : Wall voltage, Memory coefficient, Luminous efficiency, AC plasma display panel (AC-PDP)

\section{INTRODUCTION}

In ac plasma display panel (AC-PDP), sustain pulsewidth plays an important role of improvement on the operating margin and luminous efficiency. It is therefore of great importance to investigate experimentally the influence of sustain pulse-width on the electrical characteristics and luminous efficiency in AC-PDP to determine the optimal sustain pulse-width. Thus, the operating margin and the luminous efficiency as well as wall charges and wall voltages are experimentally measured in terms of the sustain pulse-width in the range of $1 \mu \mathrm{s}$ to $5 \mu \mathrm{s}$.

\section{EXPERIMENTAL CONFIGURATION}

Figure 1 shows the cross sectional view of AC-PDP cell structure. In surface discharged AC-PDP with three electrodes system, the $\mathrm{X}$ and $\mathrm{Y}$ electrodes that are covered with dielectric layers of $30 \mu \mathrm{m}$ in thickness are parallel to each other in front glass. A $\mathrm{MgO}$ protective layer is deposited on the dielectric layer by the electron beam evaporation method with $0.5 \mu \mathrm{m}$. thickness[1]. The cell pitch is fixed to be $1080 \mu \mathrm{m}$ and the width and gap of the electrode are kept to be $260 \mu \mathrm{m}$ and $100 \mu \mathrm{m}$, respectively. On the rear glass the address electrodes of $100 \mu \mathrm{m}$ in width and barrier rib of $120 \mu \mathrm{m}$ in height are located perpendicular to the two sustaining electrode[2]. Three capacitances $\mathrm{Co}, \mathrm{Cp}$ and $2 \mathrm{Cg}$, shown in Fig. 1, are for gas-filled discharge space, for intergap dielectric region, including the front glass medium which is parallel to the discharge region, and for dielectrics, respectively. The number of discharge cells for three paired XY-line is 834. In this experiment a square driving voltage pulse with rising time of $300 \mathrm{~ns}$ is applied, while the address electrode has been floated. The filling gas is a mixture of $\mathrm{Ne}(96 \%)$ and $\mathrm{Xe}(4 \%)$, and total pressure is kept to be at 400 Torr [3]. 

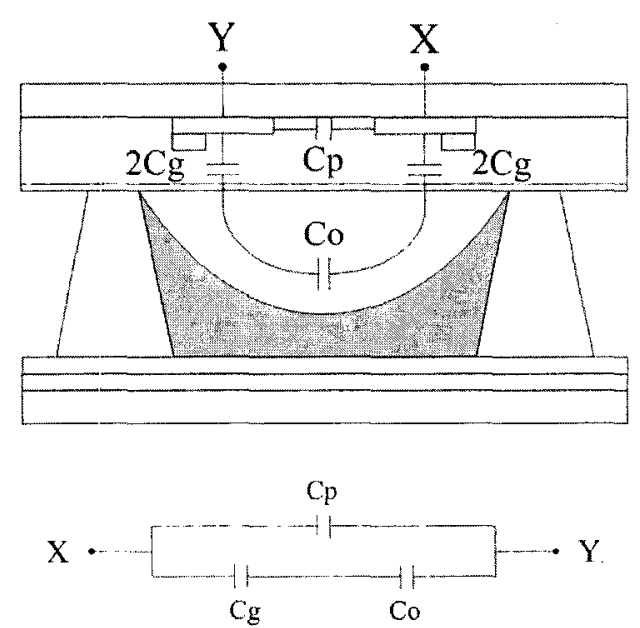

Before discharge

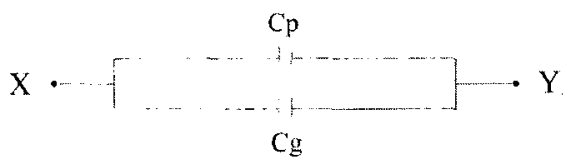

After discharge

Fig. 1. Cross sectional view of AC-PDP cell.

\section{EXPERIMENTAL RESULTS AND DISCUSSION}

Figure 2 shows the maximum wall voltages induced by accumulated wall charges between the gas-filled space, which is experimentally determined by dividing the wall charge Qw accumulated on the dielectric surface by capacitance of discharge space Co. If the sustain pulse-width is around 1 or $2 \mu \mathrm{s}$ with frequency ranges from $10 \mathrm{kHz}$ to $60 \mathrm{kHz}$, it is noted that the wall voltage has relatively small values, since it is too short to accumulate the enough wall charge on the dielectric material. It is also noted that the pulse-width possessing maximum wall voltages is significantly shortened to be $1.3 \mu \mathrm{S}, 1.7 \mu \mathrm{S}, 2.7 \mu \mathrm{s}$, and $3.6 \mu \mathrm{S}$ for driving frequencies of $180 \mathrm{kHz}, 120 \mathrm{kHz}, 60 \mathrm{kHz}$, and $10 \mathrm{kHz}$, respectively.

Figure 3 shows measured capacitances $\mathrm{Co}, \mathrm{Cp}$, and $\mathrm{Cg}$ per unit cell versus sustain pulse-width for driving frequencies of $180 \mathrm{kHz}$. These capacitances can be determined from charge-voltage $(\mathrm{Q}-\mathrm{V})$ characteristic curve along with voltage margin relation. It is found that $\mathrm{Cg}$ decreases significantly from $76 \mathrm{pF} /$ cell to $0.8 \mathrm{pF} /$ cell as sustain pulse width increases from $1 \mu \mathrm{s}$ to $2.5 \mu \mathrm{s}$ for driving frequency of $180 \mathrm{kHz}$ while Co is almost unchanged at $0.3 \mathrm{pF} / \mathrm{cell}$. Also found is that the capacitance $\mathrm{Cp}$ has a negative capacitance characteristics, which means that the amount of charge increment $\Delta Q p$ with respect to voltage increment $\Delta \mathrm{V}$ in $\mathrm{Cp}$ is negative.

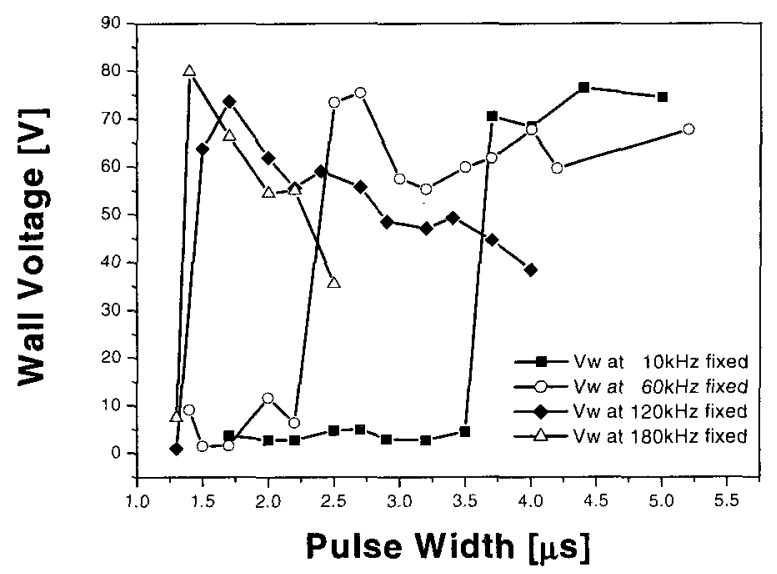

Fig. 2. Wall voltages with respect to sustain pulse-width.

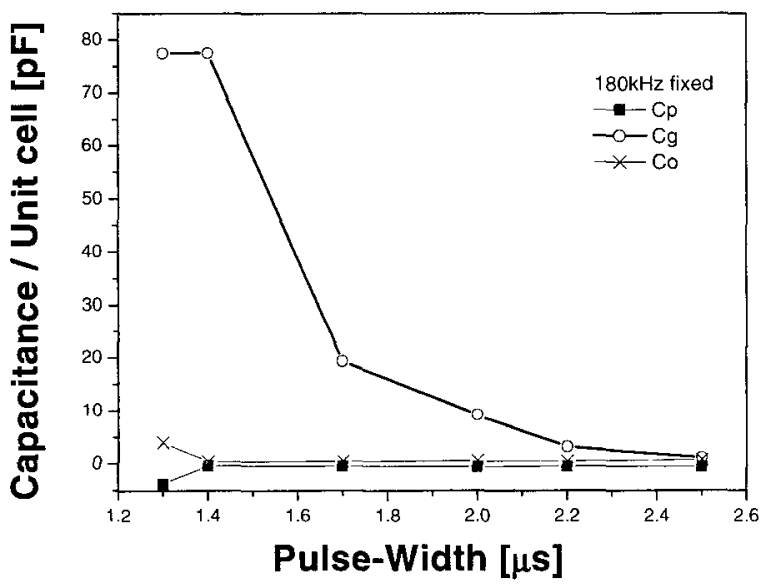

Fig. 3. Capacitances Co, $\mathrm{Cp}$, and $\mathrm{Cg}$ per unit cell.

The characteristics of negative capacitance is caused by wall charge accumulated on the dielectric surface in previous pulse[4].

Figure 4 shows the memory coefficient versus sustain pulse-width. It is noted that the memory coefficient versus sustain pulse-width has the similar characteristics to those of wall voltage, as shown in Fig. 2, for several driving frequencies used in this experiment. These characteristics are caused by both the wall charge quantities accumulated on the dielectric surface and capacitance Co. It is noted that the memory coefficient is significantly increased from 0.05 to 0.63 at pulse-width of $3.6 \mu \mathrm{s}, 2.2 \mu \mathrm{s}, 1.7 \mu \mathrm{s}, 1.3 \mu \mathrm{s}$ for driving frequencies of $10 \mathrm{kHz}, 60 \mathrm{kHz}, 120 \mathrm{kHz}, 180 \mathrm{kHz}$, respectively. These characteristics shows the existence of optimal sustain pulse duration occupying memory coefficient greater than 0.6 . 


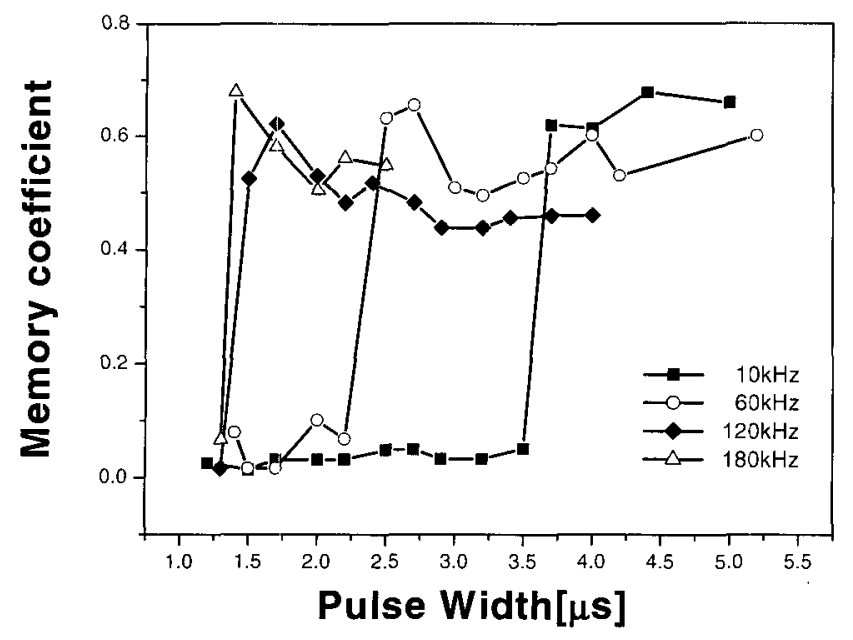

Fig. 4. Memory coefficient versus sustain pulse-width.

Figure 5 shows the luminous efficiency for various sustain pulse-width ranged from $1 \mu \mathrm{s}$ to $5 \mu \mathrm{s}$ at fixed driving frequencies of $10 \mathrm{kHz}, 60 \mathrm{kHz}, 120 \mathrm{kHz}$ and 180 $\mathrm{kHz}$, respectively. The luminous efficiency is defined as following.

Efficiency $=(\pi \times$ lighting area $\times$ brightness $) /$

(power consumption of discharge)

The power is calculated from voltage and current waveforms. It is noted that the luminous efficiency shows the slight increment in all sustain pulse-width region. It is noted that the luminous efficiency for 10 $\mathrm{kHz}$ and $180 \mathrm{kHz}$ are $1.29 \mathrm{~lm} / \mathrm{W}$ and $0.68 \mathrm{~lm} / \mathrm{W}$ respectively, since the power consumption for $10 \mathrm{kHz}$ is much less than that for $180 \mathrm{kHz}$ as shown in Fig. 5. It has been concluded that the optimal sustain pulse-width is in the range of $2.5 \sim 4.5 \mu \mathrm{s}$ under driving frequency range of $10 \mathrm{kHz}$ and $60 \mathrm{kHz}$, and is in the range of $1.5 \sim 2.5 \mu \mathrm{s}$ under driving frequency range of $120 \mathrm{kHz}$ and $180 \mathrm{kHz}$ based on observations of wall voltage and memory coefficient as well as luminous efficiency. It is also noted that the higher brightness is obtained for higher driving frequencies for given pulse-width[5].

\section{CONCLUSION}

It is found that the brightness has been nearly unchanged by pulse-width for given driving frequencies. Influence of sustain pulse-width on the electrical characteristics and luminous efficiency have been experimentally investigated to determine the optimal sustain pulse-width in the surface discharge of AC-PDP.

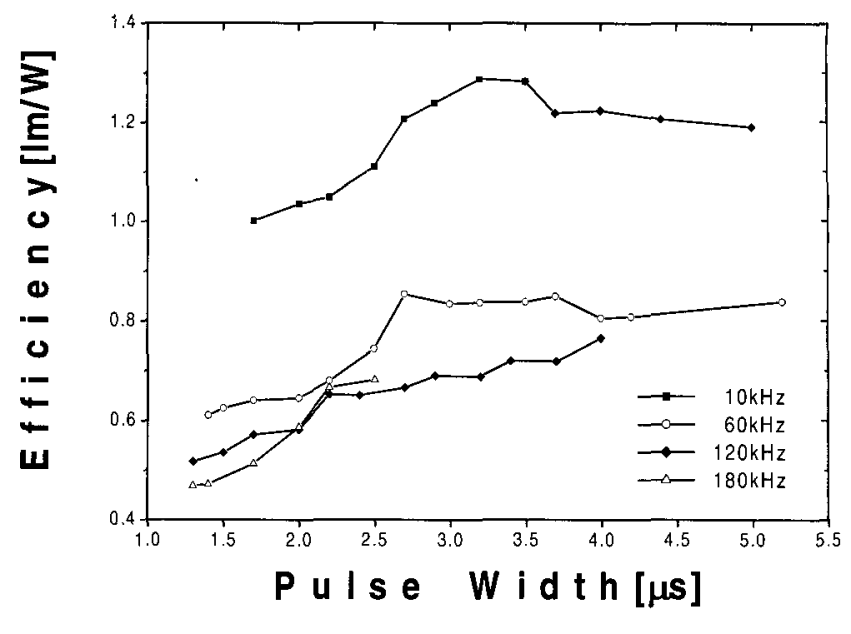

Fig. 5. Luminous efficiency versus sustain pulse-width.

It is noted that the wall voltage versus pulse-width has the similar characteristics to that of memory coefficient. These characteristics are caused by both the wall charge quantities accumulated on dielectric surface and the measured capacitance Co. It has been found that the capacitances $\mathrm{Cp}$ are found to be negative capacitance characteristics which is originated from wall charge deposited on the dielectric material. It has been also found that the memory coefficient is significantly increase from 0.05 to 0.63 , at respective sustain pulsewidth region between $1 \mu \mathrm{s}$ and $5 \mu \mathrm{s}$ for respective driving frequencies. Consequently the optimal pulsewidth is existed. If the pulse-width is in optimal value, then the operating margin is enlarged because of the wall voltage increment induced by the more accumulated wall charge. It is noted that the luminous efficiency for 10 $\mathrm{kHz}$ and $180 \mathrm{kHz}$ are $1.29 \mathrm{~lm} / \mathrm{W}$ and $0.68 \mathrm{~lm} / \mathrm{W}$ respectively, since the power consumption for $10 \mathrm{kHz}$ is much less than that for $180 \mathrm{kHz}$.

It has been concluded that the optimal sustain pulsewidth is in the range of $2.5 \sim 4.5 \mu$ s under driving frequency range of $10 \mathrm{kHz}$ and $60 \mathrm{kHz}$, and is in the range of $1.5 \sim 2.5 \mu \mathrm{S}$ under driving frequency range of $120 \mathrm{kHz}$ and $180 \mathrm{kHz}$ based on the observations of wall voltage, and memory coefficient as well as luminous efficiency.

\section{ACKNOWLEDGMENTS}

One of authors (Y. J.) would like to express sincere thanks to Mr. S. O. Cho and Prof. T. W. Kim of Hong-ik University for their profound encouragement and useful comments on the manuscript. This work financially supported by the Ministry of Education and Human Resources Development(MOE), the Ministry of 
Commerce, Industry and Energy(MOCIE) and the Ministry of Labor(MOLAB) through the fostering project of the Lab of the Excellency.

\section{REFERENCES}

[1] J. M. Jeoung, J. Y. Lim, Y. G. Kim, Y. Seo, G. Cho, and E. H. Choi, "Influence of vacuum-annealing process on the secondary electron emission coefficient $(\gamma)$ from a $\mathrm{MgO}$ protective layer", Jpn. J. Appl. Phys., Vol. 40, p. 1433, 2001.

[2] A. K. Varshneya, "Fundamentals of Inorganic Glass", Academic Press, p. 353, 1994.
[3] J. P. Boeuf, "Plasma display panels: physics, recent developments and key issues", J. Phys. D: J. Appl. Phys., Vol. 36, p. 53, 2003.

[4] E. H. Choi, T. S. Cho, D. S. Cho, M. C. Choi, J. G. Kim, S. S. Kim, M. W. Chong, S. H. Choi, Y. G. Kim, J. J. Ko, D. I. Kim, C. W. Lee, Y. H. Seo, G. Cho, and H. S. Uhm, "Influence of driving frequency on the system parameters in surface discharge of AC plasma display panels", Jpn. J. Appl. Phys., Vol. 38, p. 6073, 1999.

[5] H. B. Hsu, C. L. Chen, S. Y. Lin, and Kelvin Lee, "Regenerative power electronics driver for plasma display panel in sustain mode operation", IEEE Trans. Ind. Electron. Vol. 47, p. 1118, 2000. 